\title{
Influence of Kenyan phonolite manufactured sand on concrete performance
}

\author{
Xuxue Jiao ${ }^{1, *}$, Lifeng Liang ${ }^{1}$, Xin $\mathrm{Li}^{1}$, Guodong Fan ${ }^{1}$, Xiaojun Chen ${ }^{1}$ \\ ${ }^{1}$ China Road and Bridge Co., Beijing 100011, China
}

\begin{abstract}
There is a shortage of river sand and a large number of phonolite deposits around Nairobi, Kenya, but the quality of manufactured sand made from phonolite is poor. In this paper, the effects of phonolite manufactured sand and river sand on the performance of C30 and C50 concrete are studied through the tests of mixture performance, mechanical properties and durability. The results showed that compared with the concrete prepared with river sand, the dosage required of superplasticizer in the preparation of concrete using phonolite manufactured sand was higher, the fluidity was slightly lower, the mechanical properties were basically unchanged, and the durability was slightly better. The above research results preliminarily indicate that it is feasible to use the manufactured sand produced by phonolite around Nairobi, instead of river sand, to prepare concrete. This will reduce the long-distance procurement and transportation of river sand and reduce project construction costs.
\end{abstract}

\section{Introduction}

The main line of Nairobi expressway project in Kenya is $27 \mathrm{~km}$ long, with a design speed of $80 \mathrm{~km} / \mathrm{h}$, which is a national highway of a grade. The river sand resources around Nairobi are scarce, but the mine resources are rich. The project department considers using the rocks on the mine to produce manufactured sand to prepare high strength concrete. Manufactured sand has been widely used in highway construction in China.

Zheng et al. [1] studied the preparation of C50 prefabricated T-beams with manufactured sand processed from granite in the tunnel, and showed that manufactured sand and gravel aggregates produced from granite can be used to prepare C50 concrete T-beams with excellent workability, mechanical properties and durability, and the stiffness, strength and crack resistance of the concrete T-beam meet the design requirements. $\mathrm{Li}$ et al. [2] compared the workability, mechanical properties and durability of concrete prepared by river sand and manufactured sand produced by limestone with a high-stone powder content. The results showed that when the MB value of limestone powder was 0.2 and the content of limestone manufactured sand powder was as high as $15 \%$, it was possible to prepare manufactured sand concrete that had the workability, mechanical properties and durability of RSS (RSS) or exceeded that of RSS, and at the same time, the produce of unilateral concrete could save nearly $40 \mathrm{~kg}$ of cement. Li et al. [3] studied the application of manufactured sand for the preparation of C50 T-beams, and showed that T-beams did not find cracks and other abnormal phenomena, the force met the design requirements, and was in the elastic working range under the applied load. Gao et al. [4] studied the properties of manufactured sand in 10 bid sections of an expressway, and systematically investigated the preparation technology, workability, mechanical properties and durability of manufactured sand concrete. Zhou [5], Li [6], Li [7] and Yang [8], et al. have studied the influence of different sand-making technology, lithology, and stone powder content on the performance of concrete, all of which can meet the requirements of highway engineering concrete.

The above research provides a certain technical basis for the application of phonolite manufactured sand in highway engineering, but the mines around Nairobi are mainly phonolite mines, which have large crushing value and water absorption, and the research on the application of phonolite manufactured sand in concrete is less. In this paper, a comparative study of phonolite manufactured sand and river sand in Nairobi was conducted to provide technical support for the application of phonolite manufactured sand in concrete of Nairobi expressway project.

\section{Material and testing method}

\subsection{Raw material}

(1) Cement: CEM I 42.5 cement whose water consumption of standard consistency is $26 \%$, initial setting is $165 \mathrm{~min}$, final setting is $267 \mathrm{~min}, 3 \mathrm{~d}$ and $28 \mathrm{~d}$ compressive strength are $27.1 \mathrm{MPa}$ and $52.3 \mathrm{MPa}$ respectively.

(2) Fine aggregate: the fineness modulus of natural river sand in Kenya is 2.6 , and the mud content is $0.7 \%$; the fineness modulus of manufactured sand produced by

\footnotetext{
* Corresponding author: jiaoxx@crbc.com
} 
moderately weathered phonolite is 2.9 , the stone powder content is $6 \%$, the MB value is 1.3 , the saturated surface dry water absorption is $2.3 \%$, and the crushing value is $23.7 \%$.

(3) Coarse aggregate: $5 \mathrm{~mm}-25 \mathrm{~mm}$ continuous graded granite gravel was used.

(4) Fly ash: Grade II fly ash imported from India with a fineness ( $45 \mu \mathrm{m}$ sieve residue) of $14.6 \%$, and a water demand ratio of $98 \%$ was used.

(5) The additive is polycarboxylate superplasticizer with solid content of $15.6 \%$ and water reducing rate of $21.2 \%$.

\subsection{Mix proportion}

This experiment referred to the Chinese Standard General Concrete Mix Proportion Design Regulations (JGJ 55-2011) to prepare C30 and C50 strength grade concrete respectively. The letter $\mathrm{H}$ stood for river sand and $\mathrm{J}$ for manufactured sand. The concrete mix proportion of each group was shown in Table 1.

Table 1 Mix proportion of concrete $\left(\mathrm{kg} / \mathrm{m}^{3}\right)$

\begin{tabular}{|c|c|c|c|c|c|c|c|}
\hline Sample ID & Strength grade & Cement & Fly ash & Fine aggregate & Coarse aggregate & Water & Superplasticizer \\
\hline C30H & C30 & 300 & 70 & 812 & 1032 & 162 & 3.21 \\
\hline C30J & C30 & 300 & 70 & 812 & 1032 & 162 & 3.54 \\
\hline C50H & C50 & 440 & 50 & 735 & 1016 & 160 & 4.20 \\
\hline C50J & C50 & 440 & 50 & 735 & 1016 & 160 & 4.63 \\
\hline
\end{tabular}

Table 2 Influence of river sand and phonolite manufactured sand on workability of concrete

\begin{tabular}{|c|c|c|c|c|c|c|}
\hline $\begin{array}{c}\text { Sample } \\
\text { ID }\end{array}$ & $\begin{array}{c}\text { Strength } \\
\text { grade }\end{array}$ & $\begin{array}{c}\text { Superplasticizer } \\
\left(\mathrm{kg} / \mathrm{m}^{3}\right)\end{array}$ & $\begin{array}{c}\text { Initial slump } \\
(\mathrm{mm})\end{array}$ & $\begin{array}{c}\text { Initial slump-flow } \\
(\mathrm{mm})\end{array}$ & $\begin{array}{c}\text { 1h slump } \\
(\mathrm{mm})\end{array}$ & $\begin{array}{c}\text { 1h slump-flow } \\
(\mathrm{mm})\end{array}$ \\
\hline C30H & C30 & 3.21 & 235 & 575 & 195 & 400 \\
\hline C30J & C30 & 3.54 & 235 & 570 & 170 & 350 \\
\hline C50P & C50 & 4.20 & 240 & 640 & 205 & 460 \\
\hline C50J & C50 & 4.63 & 235 & 625 & 175 & 390 \\
\hline
\end{tabular}

\subsection{Testing method}

The workability of concrete was tested according to the Chinese Standard Standard for test method of performance on ordinary fresh concrete: GB/T 500802016; the mechanical performance was tested according to the Chinese Standard Standard for test method of concrete physical and mechanical properties: $G B / T$ 50081-2019; the durability was tested according to the Chinese standard Standard for test methods of long-term performance and durability of ordinary concrete: $G B / T$ 50082-2009.

\section{Result and discussion}

\subsection{Workability}

The performance comparison of C30 and C50 concrete mixtures with river sand and phonolite manufactured sand was shown in Table 2. It could be seen from Table 2 that when the initial slump and initial slump-flow of $\mathrm{C} 30$ and $\mathrm{C} 50$ concrete mixtures of river sand and phonolite manufactured sand were similar, the dosage of superplasticizer for C30 and C50 RSS were $3.21 \mathrm{~kg} / \mathrm{m}^{3}$ and $4.20 \mathrm{~kg} / \mathrm{m}^{3}$, respectively, and the dosage of superplasticizer for C30 and C50 PMSC (PMSC) were $3.54 \mathrm{~kg} / \mathrm{m}^{3}$ and $4.63 \mathrm{~kg} / \mathrm{m}^{3}$, respectively, which are nearly $10 \%$ higher than that of RSS. This is mainly due to the fact that the dry water absorption of the saturated surface of phonolite manufactured sand was as high as $2.3 \%$, and the phonolite manufactured sand adsorbed a certain amount of superplasticizer and water.
On the other hand, the $1 \mathrm{~h}$ slump loss of $\mathrm{C} 30$ and $\mathrm{C} 50$ RSS were $40 \mathrm{~mm}$ and $35 \mathrm{~mm}$ respectively, and the $1 \mathrm{~h}$ slump-flow loss were $175 \mathrm{~mm}$ and $170 \mathrm{~mm}$ respectively; the $1 \mathrm{~h}$ slump loss of C30 and C50 PMSC were $65 \mathrm{~mm}$ and $60 \mathrm{~mm}$ respectively, and the $1 \mathrm{~h}$ slump-flow loss were $220 \mathrm{~mm}$ and $235 \mathrm{~mm}$ respectively; the time loss of $\mathrm{C} 30$ and C50 PMSC is greater than that of RSS, which was also closely related to the high water absorption of phonolite manufactured sand.

\subsection{Mechanical property}

The mechanical properties of C30 and C50 concrete mixed with river sand and phonolite manufactured sand at different ages are studied (see Fig. 1). The compressive strength, splitting tensile strength and compressive elastic modulus of C30 and C50 concrete are shown in Fig. 1(a), Fig. 1 (b) and Fig. 1 (c) respectively.

It could be found from Fig. 1(a) that the compressive strength of C30 and C50 PMSC increased steadily with the extension of curing age, which was the same as that of RSS. For C30 concrete, the 3-day, 7-day, 28-day and 56-day compressive strength of PMSC were 107\%, $113 \%, 95 \%$ and $96 \%$ of RSS respectively, $3 d$ and $7 d$ compressive strength were slightly higher than that of RSS, 28d and 56d compressive strength were slightly lower; For C50 concrete, 3d, 7d, 28d and 56d compressive strength of PMSC were $112 \%, 102 \%, 98 \%$ and $104 \%$ of RSS respectively, meaning that $3 \mathrm{~d}, 7 \mathrm{~d}, 56 \mathrm{~d}$ compressive strength of PMSC were slightly higher than of RSS, only $28 \mathrm{~d}$ was slightly lower than that of RSS. Considering C30 and C50 concrete, the compressive 
strength of PMSC at different curing ages was similar to that of RSS.

Fig. 1 (b) showed that the splitting tensile strength and compressive strength of PMSC had the same development mode, and both of them increased steadily with the extension of curing age. For C 30 concrete, the $3 \mathrm{~d}, 7 \mathrm{~d}, 28 \mathrm{~d}$ and $56 \mathrm{~d}$ splitting tensile strength of PMSC were $96 \%, 94 \%, 102 \%$ and $107 \%$ of RSS, respectively, the $3 \mathrm{~d}$ and $7 \mathrm{~d}$ splitting tensile strength were slightly lower than that of RSS, and the $28 \mathrm{~d}$ and $56 \mathrm{~d}$ splitting tensile strength are slightly higher than that of RSS; For C50 concrete, the $3 \mathrm{~d}, 7 \mathrm{~d}, 28 \mathrm{~d}$ and $56 \mathrm{~d}$ splitting tensile strength of PMSC were 96\%, 94\%, 102\% and 107\% of RSS, respectively. The splitting tensile strength of PMSC was higher than that of river sand concrete in $3 \mathrm{~d}$, $7 \mathrm{~d}, 28 \mathrm{~d}$ and $56 \mathrm{~d}$. Considering C30 and C50 concrete, the splitting tensile strength of PMSC was similar to that of RSS.
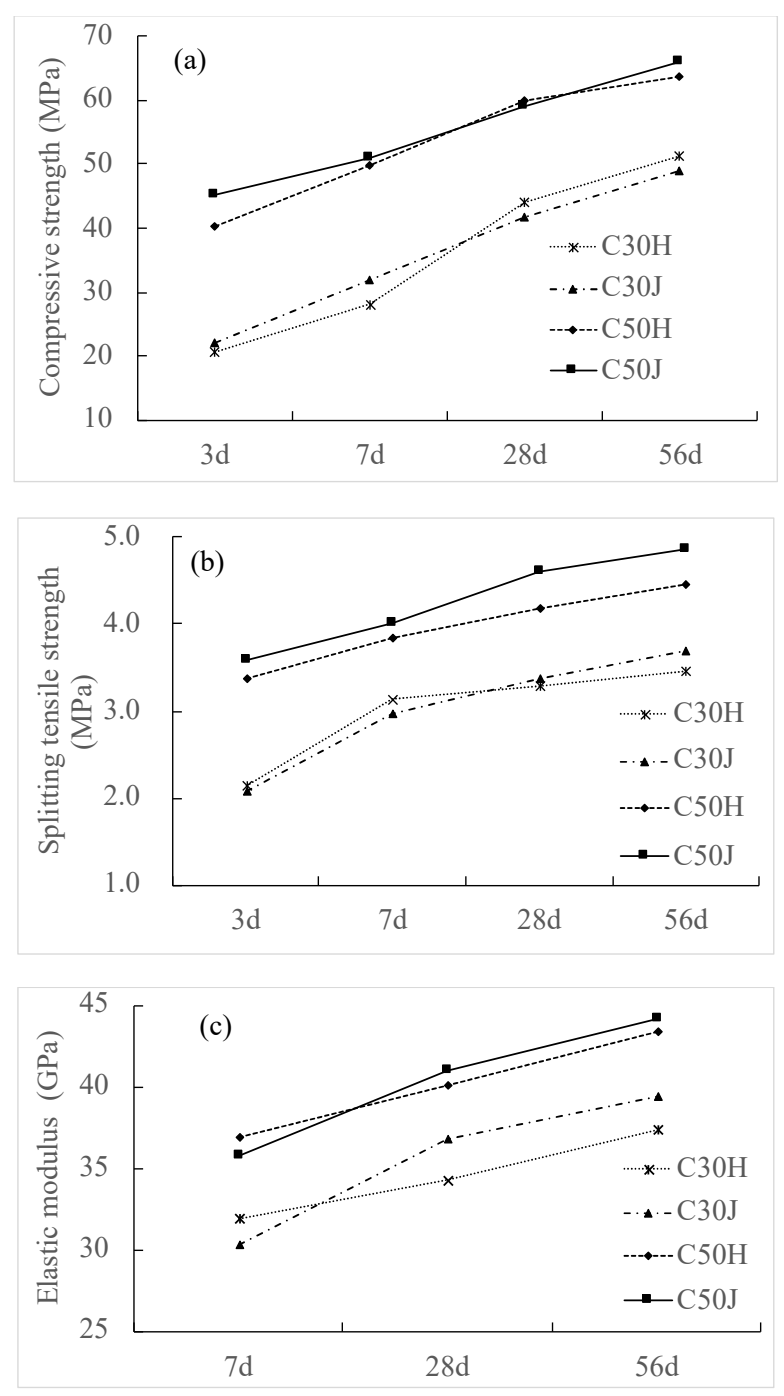

Fig. 1 Influence of river sand and phonolite manufactured sand on mechanical property of concrete: (a)Compressive strength; (b) Splitting tensile strength; (c) Elastic modulus

Fig. 3 (c) illustrated that the elastic modulus and compressive strength of phonolite manufactured sand concrete have the same development mode, and both of them increased steadily with the extension of curing age.
For $\mathrm{C} 30$ concrete, the $7 \mathrm{~d}, 28 \mathrm{~d}$ and $56 \mathrm{~d}$ modulus of elasticity of PMSC are $95 \%, 107 \%$ and $106 \%$ of RSS, respectively, the $7 \mathrm{~d}$ elastic modulus of PMSC was slightly lower than that of RSS, and the $28 \mathrm{~d}$ and $56 \mathrm{~d}$ elastic modulus of PMSC were slightly higher than that of RSS; for C50 concrete, the 7d, 28d and 56d elastic modulus of PMSC were $97 \%, 102 \%$ and $1 \%$ of RSS, respectively The elastic modulus of PMSC was slightly lower than that of RSS at 7d, and it would not affect the prestressed tension of C50 precast beam. The elastic modulus of PMSC at $28 \mathrm{~d}$ and $56 \mathrm{~d}$ were slightly higher than that of RSS. Considering C30 and C50 concrete, elastic modulus of PMSC at 7d was slightly lower than that of RSS, but with the extension of curing age, the growth rate of elastic modulus of PMSC was higher than that of RSS, and the elastic modulus of PMSC at $28 \mathrm{~d}$ and $56 \mathrm{~d}$ was higher than that of RSS.

To sum up, although the performance of PMSC was worse than that of RSS, phonolite manufactured sand has more irregular particles, stronger angularity, stronger lap and bite force than river sand. In addition, phonolite manufactured sand contains a certain amount of stone powder, which is conducive to the improvement of mechanical properties [9-11]. Therefore, the compressive strength, splitting tensile strength and elastic modulus of PMSC were similar to that of RSS, indicating that using PMSC to replace RSS would not significantly reduce the bearing capacity of concrete structure.

\subsection{Durability}

\subsubsection{Electric flux}

The electric flux of PMSC and RSS in 28d and 56d were shown in Table 3 . It could be seen that the electric flux of C30 and C50 PMSC decreased with the extension of curing age, which was the same as that of RSS. For C30 concrete, the $28 \mathrm{~d}$ and $56 \mathrm{~d}$ electric fluxes of PMSC were $98 \%$ and $94 \%$ of RSS, respectively, which were lower than of RSS; For C50 concrete, the $28 \mathrm{~d}$ and $56 \mathrm{~d}$ electric fluxes of PMSC are $94 \%$ and $93 \%$ of RSS, respectively, which are also lower than that of RSS. Considering C30 and C50 concrete, the electric flux of PMSC was slightly lower than that of RSS at $28 \mathrm{~d}$ and $56 \mathrm{~d}$, which was mainly due to the stone powder in manufactured sand promoting the formation speed of cement hydration products [12-14] making the microstructure of concrete more compact.

Table 3 Influence of river sand and phonolite manufactured sand on electric flux of concrete

\begin{tabular}{|c|c|c|}
\hline \multirow{2}{*}{ Sample ID } & \multicolumn{2}{|c|}{ Eclectic flux(C) } \\
\cline { 2 - 3 } & $28 \mathrm{~d}$ & $56 \mathrm{~d}$ \\
\hline C30H & 2335 & 1833 \\
\hline C30J & 2283 & 1714 \\
\hline C50H & 1927 & 1462 \\
\hline C50J & 1815 & 1363 \\
\hline
\end{tabular}




\subsubsection{Carbonation resistance}

The carbonation resistance of PMSC and RSS was shown in Table 4 For C30 concrete, the carbonation depth of $3 \mathrm{~d}, 7 \mathrm{~d}, 14 \mathrm{~d}$ and $28 \mathrm{~d}$ of PMSC were $5 \%, 6 \%$, $10 \%$ and $5 \%$ lower than that of RSS; for C50 concrete, the carbonation depth of $3 \mathrm{~d}, 7 \mathrm{~d}, 14 \mathrm{~d}$ and $28 \mathrm{~d}$ of PMSC were $10 \%, 6 \%, 3 \%$ and $7 \%$ lower than that of RSS. Considering $\mathrm{C} 30$ and $\mathrm{C} 50$ concrete, the carbonation depth of PMSC was slightly lower than that of RSS when carbonated for $3 \mathrm{~d}, 7 \mathrm{~d}, 14 \mathrm{~d}$ and $28 \mathrm{~d}$. This was mainly because the manufactured sand contained a certain amount of stone powder, which could optimize the pore structure of hardened paste, reduce the total pore volume of hardened paste, harmful pore volume and multi harmful pore volume $[15,16]$, so it could reduce the carbonation depth of concrete.

Table 4 Influence of river sand and phonolite manufactured sand on electric flux of concrete

\begin{tabular}{|c|c|c|c|c|}
\hline \multirow{2}{*}{$\begin{array}{c}\text { Sample } \\
\text { ID }\end{array}$} & \multicolumn{4}{|c|}{ Carbonation depth $(\mathrm{mm})$} \\
\cline { 2 - 5 } & $3 \mathrm{~d}$ & $7 \mathrm{~d}$ & $14 \mathrm{~d}$ & $28 \mathrm{~d}$ \\
\hline C30H & 4.3 & 5.4 & 6.0 & 6.2 \\
\hline C30J & 4.1 & 5.1 & 5.4 & 5.9 \\
\hline C50H & 2.1 & 3.5 & 3.9 & 4.6 \\
\hline C50J & 1.9 & 3.3 & 3.8 & 4.3 \\
\hline
\end{tabular}

\section{Conclusion}

(1) The high water absorption of phonolite manufactured sand. On the premise that the fluidity was basically the same, the usage of superplasticizer of phonolite manufactured sand concrete (PMSC) is 10\% higher than that of river sand concrete, and the loss of slump with time of PMSC was higher.

(2) The mechanical properties of PMSC were similar to those of river sand concrete due to its large amount of irregular particles, strong angularity and a certain amount of stone powder.

(3) The stone powder in phonolite manufactured sand could promote the formation rate of cement hydration products and optimize the pore structure of hardened paste. Therefore, the durability of PMSC was slightly better than that of river sand concrete.

\section{References}

1. X. Zheng, Z. Guan, C. Li, X. Huang, and B. Li, China Concrete Cement Prod. 40 (2020).

2. J. Li, B. Zhang, Y. Wang, C. Gao, Y. Zhou, Y. He, and J. Xia, Bulletin of the Chinese Ceramic Society 37, 3641 (2018).

3. T. Li, J. Wang, G. Zheng, M. Zhou, and B. Li, Concrete 35 (2009).

4. J. Gao, C. Yu, and G. Li, Highway 155 (2011).

5. H. Zhou, J. Li, R. Li, C. Gao, Y. Zhou, and J. Xia, Build. Sci. 34, 72 (2018).

6. P. Li, J. Xiong, and S. Wang, Concrete 127 (2012).

7. J. Li, J. Wang, M. Wang, J. Xia, Y. Zhou, C. Gao and H. Zhang, New Build. Mater. 45, 34 (2018).

8. L. Yang, Y. Tan, Z. Qiu, H. Li, Z. Wang, and Y. Xie, Railway Eng. 119 (2015).

9. M. Guan, G. Wang, Y. Wang, C. Wei, Z. Lai, H. Du, and Z. Liu, Constr. Build. Mater. 269, 121289 (2021).

10. X. Chen, G. Yuguang, B. Li, M. Zhou, B. Li, Z. Liu, and J. Zhou, Constr. Build. Mater. 240, 117953 (2020).

11. J. Zhang, D. Li, and Y. Wang, J. Clean. Prod. 258, 120665 (2020).

12. W. Shen, Y. Liu, Z. Wang, L. Cao, D. Wu, Y. T. Ji, C. Chen, Y. Zhuang, and J. Chen, Constr. Build. Mater. 44, 422 (2013).

13. W. Shen, Z. Yang, L. Cao, L. Cao, Y. Liu, H. Yang, Z. Lu, and J. Bai, Constr. Build. Mater. 114, 595 (2016).

14. H. Li, F. Huang, G. Cheng, Y. Xie, Y. Tan, L. Li, and Z. Yi, Constr. Build. Mater. 109, 41 (2016).

15. B. Li, J. Wang, and M. Zhou, Constr. Build. Mater. 23, 2846 (2009).

16. X. Ding, C. Li, Y. Xu, F. Li, and S. Zhao, Constr. Build. Mater. 108, 67 (2016).

17. S. Zhao, X. Ding, M. Zhao, C. Li, and S. Pei, Constr. Build. Mater. 138, 247 (2017).

18. W. Shen, Y. Liu, Z. Wang, L. Cao, D. Wu, Y. Wang, and X. Ji, Constr. Build. Mater. 172, 574 (2018).

19. W. Shen, Y. Liu, L. Cao, X. Huo, Z. Yang, C. Zhou, P. He, and Z. Lu, Constr. Build. Mater. 143, 312 (2017).

20. R. Yang, R. Yu, Z. Shui, C. Guo, S. Wu, X. Gao, and P. Peng, Cement and Concrete Comp. 99, 203 (2019).

21. Q. Ren, G. D. Schutter, Z. Jiang, and Q. Chen, Constr. Build. Mater. 207, 218 (2019).

22. H. Yang, D. Liang, Z. Deng, and Y. Qin, Constr. Build. Mater. 188, 1045 (2018).

23. A. J. Prithika and S. K. Sekar, Constr. Build. Mater. 103, 1 (2016).

24. B. Li, G. Ke, and M. Zhou, Constr. Build. Mater. 25, 3849 (2011).

25. P. Nanthagopalan and M. Santhanam, Cement and Concrete Comp. 33, 353 (2011). 